\title{
Anomalous origin of the left coronary artery from the pulmonary trunk: repair after diagnostic cross sectional echocardiography
}

\author{
SAADEH B JUREIDINI, * SORAYA NOURI, * D GLENN PENNINGTON† \\ From the Section of Cardiology, Department of Pediatrics and Adolescent Medicine, and the $\nmid$ Division of \\ Cardiothoracic Surgery, St Louis University Medical Center, St Louis, Missouri, USA
}

SUMMARY An infant with anomalous origin of the left coronary artery from the pulmonary trunk presented with congestive cardiomyopathy. Only cross sectional echocardiography gave a definitive diagnosis. The results of cardiac catheterisation and angiography were inconclusive. Surgical repair was performed successfully after the results of cross sectional echocardiography were known.

There are established guidelines for the diagnosis of anomalous origin of the left coronary artery from the pulmonary trunk by cross sectional echocardiography ${ }^{1-3}$ and Doppler echocardiography. ${ }^{4}$ But as yet there are no reports of operations on patients in whom the diagnosis of anomalous origin of left coronary artery from the pulmonary trunk was based solely on echocardiography. This is probably because those workers who described the echocardiographic findings also stressed the need for cineaortography as the "definitive investigation in these patients". ${ }^{1-3}$ We describe our experience with an infant with anomalous origin of the left coronary artery from the pulmonary trunk who had a repair operation after a cross sectional echocardiographic study clearly showed the defect. The results of cardiac catheterisation were inconclusive. This case has led us to question the need for cardiac catheterisation in some cases of anomalous origin of the left coronary artery from the pulmonary trunk in which a definitive diagnosis can be made by cross sectional echocardiography.

\section{Case report}

A two month old infant was referred to our institution for management of congestive cardiomyopathy of recent onset. The history indicated episodes of "turning pale" during feeding. Physical exam-

Requests for reprints to Dr Saadeh B Jureidini, Pediatric Cardiology, Department of Pediatrics/Adolescent Medicine, St Louis University School of Medicine, St Louis, MO 63104, USA. ination showed tachypnoea, tachycardia, weak peripheral pulses, hypotension, an enlarged liver, an enlarged heart, $S_{3}$ gallop, and no murmurs. Chest $x$ ray showed an enlarged heart with pulmonary oedema. The pattern of the electrocardiogram indicated an anterolateral infarction. The patient improved on digoxin and diuretics. Cross sectional echocardiography clearly showed an anomalous left coronary artery arising from the pulmonary trunk; there was generalised hypokinesia and dilatation of the left ventricle, with paradoxical septal motion and a resultant decrease in the shortening fraction to $15 \%$. The ostium, course, and branches of the left coronary artery were demonstrated to originate from the pulmonary trunk posteriorly and slightly above the cusps of the pulmonary valve (fig a). The right coronary artery was normal. These latter views were obtained from modified high parasternal short axis cuts. ${ }^{3}$ Doppler echocardiography showed a normal flow pattern in the pulmonary artery; there was no evidence of late systolic retrograde flow, ${ }^{4}$ and moderate mitral regurgitation was detected. A thallium scan showed reduced perfusion in the anterolateral part of the myocardium, which was consistent with the echocardiographic diagnosis. ${ }^{5}$

After these non-invasive tests the patient was examined by cardiac catheterisation and angiography: there was no oxygen saturation step up in the right heart; oxygen saturation was $56 \%$ in both the right ventricle and pulmonary artery. Pressure in the pulmonary artery $(36 / 10, \overline{20} \mathrm{~mm} \mathrm{Hg})$ was half of systemic pressure while the aortic pressure was $70 / 45, \overline{60} \mathrm{~mm} \mathrm{Hg}$, with normal oxygen saturation of 


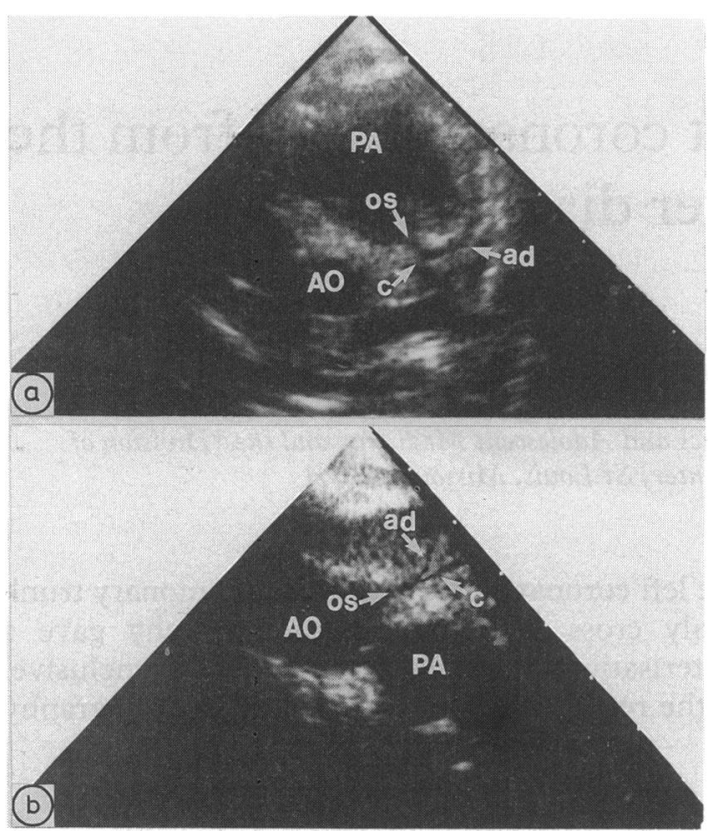

Figure (a) $A$ modified high parasternal short axis view showing the anomalous origin of the left coronary artery from the pulmonary trunk. (b) Similar view to that shown in (a) from a patient with $D$ transposition of the great arteries showing the origin of the left coronary from the anteriorly located aorta. Notice the similarity of the appearance of the coronary artery originating from the anterior great vessel to the appearance in ( $a$ ). ad, anterior descending; $A O$, aorta; c, circumflex; os, ostium of the left coronary artery; $P A$, pulmonary artery or trunk.

$96 \%$. Aortography failed to demonstrate the origin of the left coronary artery; however, the right coronary artery was well seen and was dominant giving rise to the posterior descending coronary artery. No coronary collaterals were demonstrated. Pulmonary artery injection also did not visualise the left coronary artery.

At operation a median sternotomy was made and the diagnosis of anomalous origin of the left coronary artery from the pulmonary artery was confirmed. A few small collaterals were seen in the vicinity of the anomalous coronary artery; the direction of blood flow in the anomalous coronary artery was difficult to assess. During cardiopulmonary bypass, without aortic occlusion, an end to end anastomosis was created between the left subclavian artery and the left coronary artery. The patient had an uneventful postoperative course and is alive and well 20 months after operation. He continues to take digoxin. His left ventricular shortening fraction remained marginally reduced, until his last visit 20 months ago, when it became normal at $40 \%$. The septal motion has remained dyskinetic with normal posterior wall motion. The left ventricular posterior wall and septal thickness were increased. No residual mitral regurgitation was detected by Doppler echocardiography.

\section{Discussion}

In infants the clinical presentation of anomalous origin of the left coronary artery from the pulmonary trunk can resemble that of acute viral myocarditis. ${ }^{4}$ In both conditions the electrocardiogram may show an infarction pattern. ${ }^{56}$ Similarly, the thallium perfusion scan can demonstrate perfusion defects in patients with acute viral myocarditis. ${ }^{4}$ Cross sectional echocardiography, however, has been very helpful in differentiating between the two diseases, ${ }^{2}$ specifically if the diagnosis of the former is made by direct visualisation of the anomalous origin of the left coronary artery from the pulmonary trunk, rather than by demonstrating the absence of this artery from the aorta. ${ }^{1}$

A dilated right coronary artery is another cross sectional echocardiographic sign of this anomaly. This dilatation is thought to be secondary to the presence of collaterals supplying the left coronary artery from the right. ${ }^{23}$ In this patient, the presentation was early and probably occurred before the development of collaterals that were large enough to produce a left to right shunt in the pulmonary artery that was detectable either by Doppler echocardiography or cardiac catheterisation. This would also explain the failure of retrograde filling of the left coronary artery and the absence of dilatation of the right coronary artery. ${ }^{7}$

In this case cardiac catheterisation and angiography did not add any information to the diagnosis already made by cross sectional echocardiography and these invasive investigations exposed the infant to additional risks. Some might argue that additional information could be obtained by cardiac catheterisation, for example definition of associated lesions such as anomalous origin of the right coronary artery from the pulmonary trunk. ${ }^{7}$ The presence of such an abnormality, however, will not affect surgical management because isolated anomalous origin of the right coronary artery from the pulmonary trunk is benign and usually does not require surgical correction. ${ }^{7}$ We propose that after surgical repair and return of ventricular function to normal ${ }^{8}$ the risks of cardiac catheterisation will be reduced and other abnormalities will be more easily detected.

Cross sectional echocardiographic examination can give false positive results when it is used to diagnose this anomaly. ${ }^{1}$ Nevertheless, we know from our experience of using cross sectional echo- 
cardiography to diagnose transposition of the great arteries that when the origin and course of the left coronary artery from the anterior vessel (the aorta) is demonstrated a false positive diagnosis is unlikely. In $10(91 \%)$ of the last eleven consecutive patients with transposition of the great arteries (six males and four females, age 1-90 days), in whom cross sectional echocardiography was used to study the anatomy of the left coronary artery, we were able to demonstrate the origin, course, and proximal branches of the left coronary artery and clearly demonstrate that this originated from the aorta (91\%) (fig b). These patients had confirmatory angiographic studies. In anomalous origin of the left coronary artery from the pulmonary trunk in our present patient (fig a and b), and in transposition of the great arteries the left coronary artery originating from the anterior vessels produced similar cross sectional echocardiographic appearances.

This case report indicates that cross sectional echocardiography is a sensitive means of diagnosing an anomalous origin of the left coronary artery from the pulmonary trunk. If this proves to be a consistent finding, the additional risks of cardiac catheterisation and angiography could be avoided in patients with this condition.

We thank Dr S C Chen and Dr I C Balfour for helping us to prepare this paper.

\section{References}

1 Robinson PJ, Sullivan ID, Kumpeng V, Anderson RH, Macartney FJ. Anomalous origin of the left coronary artery from the pulmonary trunk: potential for false negative diagnosis with cross sectional echocardiography. Br Heart $J$ 1984;52:272-7.

2 Caldwell RL, Hurwitz RA, Girod DA, Weyman AE, Feigenbaum $H$. Two-dimensional echocardiographic differentiation of anomalous left coronary artery from congestive cardiomyopathy. Am Heart J 1983; 106:710-6.

3 Fisher EA, Sepehri B, Lendrum B, Luken J, Levitsky S. Two-dimensional echocardiographic visualization of the left coronary artery in anomalous origin of the left coronary artery from the pulmonary artery: pre and postoperative studies. Circulation 1981;63: 698-704.

4 King DH, Danfard DA, Huhta JC, Gutgesell HP. Noninvasive detection of anomalous origin of the left main coronary artery from the pulmonary trunk by pulsed Doppler echocardiography. Am J Cardiol 1985;55:608-9.

5 Gutgesell HP, Pinsky WW, DePuey EG. Thallium-201 myocardial perfusion imaging in infants and children: value in distinguishing anomalous left coronary artery from congestive cardiomyopathy. Circulation 1980;61:596-9.

6 Woods JD, Nimmo MJ, Mackay-Scollay EM. Acute transmural myocardial infarction associated with active coxsackie virus $B$ infection. Am Heart $J$ 1975;89:283-7.

7 Lurie PR, Takahashi M. Abnormalities and diseases of the coronary vessels. In: Adams FH, Emmanouilides GC, eds. Moss' heart disease in infants, children, and adolescents. Baltimore and London: Williams and Wilkins, 1984:501-16.

8 Yoshida Y, Emmanouilides GC, Nelson RJ, Baylen BG, Criley JM. Anomalous origin of the left coronary artery from the pulmonary artery: a case report with remarkable improvement of myocardial function following subclavian artery-coronary artery anastomosis. Cathet Cardiovasc Diagn 1980;6: 292-303. 